\title{
I recognize your face but I can't remember your name: Further evidence on the tip-of-the-tongue phenomenon*
}

\author{
A. DANIEL YARMEY \\ University of Guelph, Guelph, Ontario, Canada
}

\begin{abstract}
Fifty faces of "famous" persons were used as stimuli to precipitate the tip-of-the-tongue (TOT) experience. Results showed that Ss in TOT states searched for target's name by locating first his profession, where he was most often seen, and how recently. Ss also had accurate knowledge of the initial letters of target names, initial letters of similar sounding names, and numbers of syllables in target names. It was concluded that TOT states for to-be-remembered names are retrieved from semantic and episodic memory systems on the basis of verbal and imaginal encodings.
\end{abstract}

William James (1893) first drew attention to the peculiar experiences involved in trying to recall a forgotten name, knowing and feeling how close we are, being aware of improper matches, but vainly groping in our inability to retrieve. Brown and McNeill (1966) called this phenomenon "tip-of-the-tongue" (TOT) behavior. They demonstrated that words are frequently available in memory but, at least temporarily, not accessible. When Ss are in the TOT state, they are able to identify a number of characteristics of target words with a high degree of accuracy such as the number of syllables and the initial letter. The closer $S$ is to recall, the more accurate is his knowledge. Although some of the words that Ss found, as they searched their memory, could be classed as similar in meaning to the target, the majority of words were similar in sound. Other writers (e.g., Norman, 1969; Dale \& McGlaughlin, 1971) have pointed out, however, that the nature of Brown and McNeill's questionnaire may have biased Ss to generate primarily acoustically related words.

Brown and McNeill's (1966) theoretical interests, however, are consistent with the Ebbinghaus-Watson tradition in which memory is considered only in terms of a verbal memory system involving components such as phonetic, phonemic, syllabic, and semantic word properties. In the last 10 years, however, other memory systems, particularly nonverbal imagery, have been rediscovered and shown to be equally important in memory tasks (see Paivio, 1971; Richardson, 1969; Segal, 1971: Sheehan, 1972). Although the TOT state involves an inability to recall a word, it is quite likely that both verbal and nonverbal imagery codes are involved, Brown \& McNeill reported that for several months they watched the TOT state in themselves. Interestingly, when they attempted to recall the name of a particular street, the only associates they reported coming to mind were verbal. For several years, I have

*This research was supported by a grant from the National Research Council of Canada (APA 288). The author wishes to thank Jean Ann Woodhouse for her assistance in tabulating the data and Howard R. Pollio for his discussion and comments on preliminary drafts. noticed that when I try to recall the names of people, introspective experiences such as images and affect and verbal descriptions are easily aroused. This suggests that TOT experiences may involve both verbal and nonverbal imagery processes which serve to mediate this state.

The purpose of this investigation was to explore further the TOT phenomenon. The general procedures employed by Brown and McNeill were followed with one major change. Whereas Brown and McNeill precipitated TOT states by reading definitions of English words of low frequency, in the present study visual presentations of "famous" persons were given and Ss were asked to try to recall their names. Whenever $S$ was unable to think of the target's name but felt sure that he knew it and that it was on the verge of coming back, he was considered to be in the TOT state. It was expected that Ss in TOT states would elicit both imagery and verbal mediators as well as phonetic information concerning the target's name. Although verbal and imagery symbolic processes are viewed as alternative coding systems, it is also assumed that chains of verbal associates and images of events can and do occur (Paivio, 1971). No attempt was made in this study to tease apart verbal and imagery representations.

\section{METHOD}

\section{Subjects}

Fifty-three undergraduates participated in one of two sessions; each session was $2 \mathrm{~h}$ long. The Ss were volunteers from two psychology courses.

\section{Stimulus Materials}

The list consisted of 10 female and 40 male faces of "public" persons. Each stimulus was a black-and-white full-face photograph taker, from popular magazines. Thirty-five personalities came from the entertainment field (e.g., Cary Grant and Carol Burnett) and 15 came from other fields (e.g., Spiro Agnew and Pablo Picasso). Each face was cut beneath the chin and around the hairline. All stimuli were photographed and made into $35-\mathrm{mm}$ slides. 
Table 1

Frequency Selection in Completion of Categories

\begin{tabular}{|c|c|c|c|c|c|}
\hline \multirow[b]{2}{*}{ Categories } & \multicolumn{5}{|c|}{ Selections } \\
\hline & First & Second & Third & Fourth & Fifth \\
\hline Profession & 242 & 144 & 30 & 9 & 1 \\
\hline Places & 208 & 175 & 12 & 11 & 1 \\
\hline Recency & 3 & 21 & 103 & 16 & 7 \\
\hline Initial Letter of First and Last Names & 19 & 37 & 26 & 22 & 6 \\
\hline Syllables in First and Last Names & 46 & 13 & 29 & 20 & 12 \\
\hline Names of Similar Sound & 15 & 17 & 38 & 16 & 6 \\
\hline
\end{tabular}

\section{Response Sheet}

The response sheet included all but one of the categories used by Brown and McNeill (1966) plus three other response categories. The vertical columns were headed as follows: intended word ( + one I was thinking of) ( - not); number of syllables in first name; number of syllables in last name; initial letter of first name; initial letter of second name; names of similar sound (1. closest in sound) (2. middle) (3. farthest in sound); person's profession(s) or field(s) of importance; place(s) where you most often see this person; how recently? the name you were seeking if it is now available but is not the target name.

\section{Procedure}

A modified form of the instructions used by Brown and $\mathrm{McNeill}$ (1966) was employed. Since these instructions are quite lengthy, they will not be repeated here. The following changes were made. Whenever Brown and McNeill referred to "definitions and words," the terms "faces and names" were substituted. Instead of asking Ss to write down "words of similar meaning," Ss were instructed to try to recall the person's profession or field of importance, the place(s) where they most often saw this person, e.g., newspapers, television, movies, theatre, magazines, etc., and finally, how recently they had seen this person, e.g., within the last week, last month, last year, or more than a year ago? The Ss were told that they were not required to fill in the columns in a left-to-right sequence. Rather they were free to complete the columns in their own preferred order. Ss were instructed to number each column serially as they started to complete it.

In summary, the procedure consisted of presenting slides of facial photographs of "public" persons. Those Ss who were in a TOT state for a particular stimulus face completed a questionnaire designed to describe their TOT experience.

\section{RESULTS}

\section{General Information}

The total number of reported TOT instances across all faces and all Ss was 623 . Three hundred and sixty-four of these reports were positive TOTs and 259 were negative TOTs. "A positive TOT is one for which the target name is known and consequently, one for which the data obtained can be scored as accurate or inaccurate. In those cases where the target name was not the name intended but some other name which $S$ finally recalled and wrote in the right most column his data was checked against that name as his effective target. A negative TOT is one for which the $S$ judged the name read out not to have been his target and, in addition, one in which $\mathrm{S}$ proved unable to recall his own functional target [Brown \& McNeill, 1966, p. 327]."

Brown and McNeill (1966) pointed out that the general nature of TOT data violates most assumptions that underlie statistical tests of significance. For example, all stimuli did not reliably evoke TOT states; two of the faces failed to precipitate any TOTs, while the range was from 1 success to 28 . The largest number of TOT states in one $S$ was 26 , the greatest frequency of positive TOTs in one $S$ was 18 , and the highest number of negative TOTs in one $S$ was 12 . Five Ss signaled 0-5 TOTs, 17 reported 6.10 TOTs, 28 claimed 11-20 TOTs, and 3 Ss had over 20 TOT states. The Ss made actual targets of 68 names not on the original list, and all but 7 of these were sought by one S only. Some faces were clearly more easily confused than others. For example, one movie star (Ann-Margaret) was mistaken by different Ss for Marilyn Monroe, Jane Mansfield, Tuesday Weld, Lana Turner, and Angie Dickinson. Brown and McNeill refer to this type of data as fragmentary data and suggest that in spite of the limitations they be reported as fully as possible.

\section{Selection Order of Categories}

The reported order of searching memory stores for categorical information about target names is shown in Table 1. Although 623 TOTs were reported, 90 TOT instances lacked information on the sequence of category completions. Because of the relatively few guesses of the number of syllables in both first and last names and guesses of the initial letter of both names, the data in these two categories have been combined. The table suggests that in trying to remember a person's name, or at least a famous person's name, Ss first try to locate his profession and then try to remember where they most likely have seen this person. Ss then attempt to recall when they last saw this person. Other information, such as phonemic information, is available but is much less likely to be utilized early in the search. The table indicates that Ss attempted to first guess the initial letter of the names, followed closely by guesses of the number of syllables, and finally by similar sounding names. 


\section{Phonemic Information}

\section{Initial Letters}

The Ss in positive TOT states were correct on $68 \%$ of their guesses of the initial letter of first names and on $59 \%$ of guesses of the initial letter of last names. An analysis of the initial letters of names of similar sound to the target names revealed that $83 \%$ of first names and $77 \%$ of last names matched. It is difficult to estimate the chance level of success in guessing the first letter of names, but since 14 different letters of the alphabet were used for the first names and 16 different letters as: guesses, the chance level of successful matching must be low.

\section{Number of Syllables}

Over all positive TOTs, the number of syllables of the name S was seeking was correct on $73 \%$ (57 out of 79) guesses for first names and 79\% (53 out of 67) for last names. These results must be qualified by the fact that the average number of syllables in first and last names was only 1.7 and 1.8 , respectively. Consequently, the chance level of successful guessing must be high. The number of syllables in similar sounding first and last names as the target was guessed correctly $83 \%$ (25 out of 30 ) and $77 \%$ (17 out of 22) of the time, respectively, for both cases. Although Ss were asked to rank order the names of similar sound in terms of the degree of their seeming resemblance to the target, this was done by only one S. This particular S "knew" who Liza Minelli was and tried to find her name by writing out (1) Monetti, (2) Mona, (3) Magetti, (4) Spaghetti, (5) Bogette.

\section{Symbolic Representations}

The data for both positive and negative TOTs were combined and analyzed in terms of their specificity of S's information about the target's professions or fields of importance and those places (e.g., movies, television, book or particular magazines, theatre, etc.) where the target is most often seen and how recently. Specificity was defined as: (1) High-S was exact in describing the professions and places and gave precise examples, e.g., for the target "Elliot Gould" one S reported, "He is a movie star, latest film was Bob, Carol, Ted and Alice." (2) Moderate-S gave a good but not exact description, e.g., for the target "Glen Campbell" one S reported, "T.V. specials, on Smothers Brothers." (3) General-S had some knowledge but was vague, e.g., for the target "Ernie Ford" one S reported "comic in movies." And (4) Low-S was very vague, e.g., for the target "Arthur Godfrey" one S reported he was "in show business and is seen in newspapers." If $S$ claimed to have seen this person within the last week, his statement was classified as highly specific; within the last month, moderate: within the last year, general; and over a year ago, low in
Table 2

Frequency Scores of Specificity of Information on Target's Profession, Place, and Recency

\begin{tabular}{lrrrr}
\hline & \multicolumn{4}{c}{ Specificity } \\
\cline { 2 - 5 } & High & Moderate & General & Low \\
\hline Profession & 197 & 71 & 24 & 15 \\
Place & 14 & 254 & 4 & 1 \\
Recency & 8 & 32 & 93 & 31 \\
\hline
\end{tabular}

specificity. Table 2 shows the frequency scores of specificity classifications on the target's profession, place most often seen, and how recently. Ss' knowledge about the target's profession, reportedly, is highly specific, while knowledge of where the target is most often seen is moderately specific. Since these targets were "famous" persons, Ss' reports of having seen these persons more frequently in the last year rather than in the last month, for example, seems to have face validity.

\section{Proximity to the Target and Quality of Information}

Brown and McNeill (1966) made a distinction among three types of positive TOT states that is relevant also in this investigation: "... (1) Cases in which S recognized the name read by $E$ as the name he had been seeking; (2) Cases in which $S$ recalled the intended name before it was read out; (3) Cases in which S recalled the name he had been seeking before $E$ read the intended name and the recalled name was not the same as the name read... [p. 331]." Brown and McNeill state that since Ss in a Type 2 or Type 3 state found the target name before it was read and Ss in a Type 1 state did not, the TOTs of Type 1 may be considered further away from the target than Type 2 and Type 3 TOTs. The prediction is made, therefore, that Ss in Type 2 and Type 3 TOTs would have more accurate information (recall) about the target than Ss in Type 1 TOTs (recognition).

The hypothesis was tested on the guesses of the targets' professions or fields of importance and places where the targets are most frequently seen. Ss in the Type 1 TOT state were correct on $91.9 \%$ (113 out of 123) of their guesses of the targets' profession and $94.9 \%$ (111 out of 117) correct on "place" guesses. Type 2 TOT states yielded $98.7 \%$ (153 out of 156) correct guesses for "professions" and $98.6 \%$ (141 out of 143) correct guesses for "location." For Ss in Type 3 TOT states, 93.8\% (30 out of 32) of "profession" guesses were correct and 97\% (32 out of 33) of "place" guesses were correct. Although these percentage scores are greater, as predicted for Type 2 and Type 3 TOTss, than for Type 1 TOTs, the only statistically significant difference occurred between Types 1 and 2 regarding professions $\left(\chi^{2}=5.96, \mathrm{df}=1, \mathrm{p}<.02\right)$. The differences between TOT states for Types 1 and 2 regarding locations fell just short of significance $\left(\chi^{2}=3.00, \mathrm{df}=1\right.$, $.05>\mathrm{p}<.10$ ). 


\section{DISCUSSION}

These results add support to Brown and McNeill's (1966) "generic" recall interpretation of memory, i.e., partial recall of letters, syllables, affix, word class, and abstract recall, such as placement of primary stress. In this study, phonemic information of to-be-remembered names was available and consistently accurate. Ss were able to guess correctly initial letters of target names, initial letters of similar sounding names, and numbers of syllables in target names. Similar to words, names of people obey certain sequential and syntactical letter and syllabic constraints as well as phonetic generalizations. Although retrieval from generic memory is important in searching for target names, it is secondary to retrieval from other memory stores such as verbal and imagery representations. Ss' descriptions of their memory search during TOT states clearly involved both imagery and verbal mediators. While these reports do not prove a causal relationship, they are descriptive of subjective associative experiences. The predominant encoding strategy of "person information" was in a spatial form, i.e., Ss were highly specific in describing the target's profession, they were able to describe accurately where they most often saw the target, and finally, they were able to give temporal-spatial relationships to this experience. Since the majority of these public persons, reportedly, were last seen between 1 and 12 months ago, the long-term retention of this information must be stable and highly consolidated. These temporal-spatial organizations of TOT states appear to be related to Tulving's (1972) hypothesis of episodic memory. Tulving does not explicitly refer to imagery processes, but rather describes episodic memory in terms of autobiographical events which are stored in terms of temporally dated episodes and temporal-spatial relationships among these events. Perceptual events that are stored in episodic memory are encoded in terms of their perceptible (imaginal?) properties or attributes and are retrieved without reference tc rules or other cognitive processes.

In conclusion, this study shows that tip-of-the-tongue behavior is not limited to acoustically related words. Rather, depending upon the nature of the task, generic, verbal, and imaginal symbolic representations, at least, are involved in TOT experiences. In addition, TOT states seem to operate both in semantic long-term memory as well as in the more perceptual episodic memory system. Although verbal representations are the targets in TOT states, several retrieval systems are used to locate the to-be-remembered name.

\section{REFERENCES}

Brown, R., \& McNeill, D. The "tip of the tongue" phenomenon. Journal of Verbal Learning \& Verbal Behavior, 1966, 5, 325-337.

Dale, H. C. A., \& McGlaughlin, A. Evidence of acoustic coding in long-term memory. Quarterly Journal of Experimental Psychology, 1971, 23, 1-7.

James, W. The principles of psychology. Vol. 1. New York: Holt, 1893.

Norman, D. A. Memory and attention. Toronto: Wiley, 1969.

Paivio, A. Imagery and verbal processes. New York: Holt, Rinehart \& Winston, 1971

Richardson, A. Mental imagery. New York: Springer, 1969.

Segal, S. J. (Ed.) The adaptive functions of imagery. New York: Academic Press, 1971.

Sheehan, P. W. (Ed.) The function and nature of imagery. New York: Academic Press, 1972.

Tulving, E. Episodic and semantic memory. In E. Tulving and W. Donaldson (Eds.), Organization and memory. New York: Academic Press, 1972.

(Received for publication February 5, 1973; accepted February 11, 1973.) 